О. Л. Беспалов, К. Д. Соколов, С. В. Приходько ООО «Побужский ферроникелевый комбинат», пгт Побужское, Украина

А. Н. Овчарук /Д. т. н./, М. И. Гасик /Д. т. н./, О. В. Замковой, А. А. Надточий /к. т. н./

Национальная металлургическая академия

Украины, г. Днипро, Украина

\title{
Термодинамическая модель процесса десульфурации чернового ферроникеля в ковше
}

\section{O. L. Bespalov, K. D. Sokolov, S. V. Prikhodko}

A. N. Ovcharuk /Cand. Sci. (Tech.)/, M. I. Gasik /Dr. Sci. (Tech.)/, O. V. Zamkovoy, A. A. Nadtochy /Cand. Sci. (Tech.)/
Pobuzhsky Ferronickel Plant LLC, Pobuzhskoe, Ukraine

National Metallurgical Academy of Ukraine, Dnipro, Ukraine

\section{Thermodynamic model of the process of desulfurization of a black ferronickel in a ladle}

Цель. Исследования типа и химического состава неметаллических включений при процессе десульфурации чернового фрерроникеля методом составления термодинамической модели процесса десульфурации чернового фрерроникеля.

Методика. Выполнен анализ влияния кремния и углерода в термодинамической системе на процесс десульфурации чернового фрерроникеля.

Научная новизна. Впервые составлена термодинамическая модель десульфурации чернового фрерроникеля в ковше по схеме NiS - FeS - C - Si - Na2CO3 с использованием данных промышленного производства в условиях ООО «Побужский фрерроникелевый комбинат». (Ил. З. Табл. З. Библиогр.: 5 назв.)

Ключевые слова: черновой фрерроникель, никелевое сырье, сера, углерод, кремний, кальцинированная сода, десульфурация, термодинамическая модель.

Постановка проблемной задачи. Побужский ферроникелевый комбинат, который в 2017 г. отметил свое 45-летие, был введен в эксплуатацию в декабре 1972 г. В 2000 г. преобразован в ООО «Побужский ферроникелевый комбинат» (ООО «ПФК») - единственное в Украине горно-металлургическое предприятие с технологией прямой переработки (без обогащения и окускования) до 1,5 млн т окисленной никелевой руды в год и получения до 100-120 тыс. т ферроникеля (сплава железа с никелем).

В части возрождения комбината с 2003 г. были поставлены задачи модернизации, реконструкции производства, автоматизации производственных процессов, строительства новых участков с использованием передового опыта зарубежных предприятий, лучших разработок отечественных украинских и зарубежных научно-исследовательских организаций и институтов. Конечная цель - создание полностью безотходного, экологически чистого производства ферроникеля с расходом энергетических и технологических ресурсов на единицу производимой продукции на уровне, соответствующем показателям зарубежных предприятий.

Побужский ферроникелевый комбинат изначально ориентировался на переработку отечественных окисленных никелевых руд Капитановского месторождения. Поскольку местное месторождение бедной окисленной никелевой руды в настоящее время практически выработано, комбинат перешел на импортную руду. Вначале поставлялась руда из Новой Каледонии, затем - из Индонезии. В связи с тем, что Индонезия с начала 2014 г. прекратила экспорт руды, ПФК перешел на гватемальскую руду.

В настоящее время комбинат работает на гватемальской руде, которая характеризуется более высоким содержанием никеля и оксида магния (табл. 1) по сравнению с рудой Капитановского месторождения, на базе которого был спроектирован и работал завод до 2006 г. [1].

На Побужском ферроникелевом комбинате работают две рудотермические электропечи установочной мощностью 48 МВА. 
Химический состав руд различных месторождений

\begin{tabular}{|l|c|c|c|c|c|c|c|}
\hline \multirow{2}{*}{$\begin{array}{c}\text { Наименование } \\
\text { месторождения }\end{array}$} & \multicolumn{7}{|c|}{ Химический состав, \% по массе } \\
\cline { 2 - 9 } & $\mathbf{N i}$ & $\mathrm{Fe}$ & $\mathrm{SiO}_{2}$ & $\mathrm{CaO}$ & $\mathrm{MgO}$ & $\mathrm{Cr}_{2} \mathrm{O}_{3}$ & $\mathrm{Al}_{2} \mathrm{O}_{3}$ \\
\hline Новая Каледония (2006 г.) & $\mathbf{2 , 2 2}$ & 14,89 & 38,77 & 1,11 & 20,60 & 1,66 & 1,74 \\
\hline Индонезия (2006-2012 гг.) & $\mathbf{2 , 0 8}$ & 12,62 & 42,95 & 1,05 & 21,45 & 1,18 & 1,91 \\
\hline Гватемала (2013-2016 гг.) & $\mathbf{1 , 8 8}$ & 15,66 & 34,8 & 1,23 & 22,0 & 0,98 & 2,7 \\
\hline Капитановское (Украина) & $\mathbf{0 , 8}$ & 16 & 38,5 & 17 & 4,8 & 3,5 & 2,9 \\
\hline
\end{tabular}

Электроплавку осуществляют, используя огарок с температурой $600-700{ }^{\circ} \mathrm{C}$ следующего состава, \%: 0,7-0,9 Ni; 0,03-0,05 Co; 15-18 Fe; 45-36 $\mathrm{SiO}_{2}$; 16-20 СaO; 4-6 MgO. Восстановление огарка идет за счет углерода антрацита марки (AC) или антрацитового штыба марки (АШ), энергетического угля и карбидокремниевого материала [2].

Черновой ферроникель с 10-14 \% Ni имеет высокое содержание серы, поступающей из углеродистого восстановителя, электродной массы и из руды, подвергается рафинированию от примесных элементов по сложной технологической схеме, а за тем разливается на разливочной машине или гранулируется.

Химический состав чернового ферроникеля, в зависимости от качества никельсодержащего сырья различных месторождений приведен в табл. 2. В настоящее время на Побужском ферроникелевом комбинате на РТП-1 освоена технология низкого восстановления (ТНВ). При этом содержание никеля в черновом ферроникеле повысилось до $50 \%$, а содержание кремния и углерода составило всего около 0,01 \%, что затрудняет проведение процесса ковшевой десульфурации содой. При этом повысилось содержание серы в два раза и составило около 0,5 \%, а также значительно вырос расход электродной массы (в 5-6 раз) [3].

В настоящие время для повышения эффективности процесса десульфурации было принято решение смешивать черновой ферроникель, выплавляемый по старой технологии на РТП-2, с ферроникелем, выплавляемым с недостатком восстановителя на РТП-1. Это дало возможность

несколько улучшить процесс десульфурации чернового ферроникеля в ковше. В табл. 3 приведен химический состав чернового ферроникеля на РТП-1 и РТП-2, произведенного по разным технологическим схемам.

Процесс рафинирования чернового ферроникеля выполняется в три стадии:

1. Внепечная десульфурация жидкого чернового ферроникеля содой или плавом соды [4].

2. Рафинирование от примесей углерода, кремния и хрома в вертикальных конвертерах с «кислой» футеровкой и верхней продувкой кислородом.

3. Рафинирование от серы, фосфора и доводка металла по химсоставу и температуре в вертикальном конвертере с «основной» футеровкой и верхней продувкой кислородом [5].

Внепечная десульфурация чернового ферроникеля производиться кальцинированной содой, плавом соды или их смесью в ковше для металла непосредственно при выпуске чернового ферроникеля из РТП. Процесс десульфурации кальцинированной содой основан на образовании устойчивого сульфида натрия, переходящего в шлак, и описывается реакцией:

$$
\begin{gathered}
{[\mathrm{FeS}]+2\left(\mathrm{Na}_{2} \mathrm{CO}_{3}\right)+[\mathrm{C}]+[\mathrm{Si}]=[\mathrm{Fe}]+} \\
+\left(\mathrm{Na}_{2} \mathrm{SiO}_{3}\right)+3 \mathrm{CO} \uparrow+\left(\mathrm{Na}_{2} \mathrm{~S}\right),
\end{gathered}
$$

которая приводится в многочисленных источниках научно-технической отечественной и зарубежной литературы, но не описана ее термодинамика.

В данной работе впервые предпринята попытка составить термодинамическую модель этой

Таблица 2

Химический состав чернового ферроникеля, выплавленный з сырья различных месторождений, \%

\begin{tabular}{|l|c|c|c|c|c|c|c|}
\hline \multicolumn{1}{|c|}{ Наименование } & $\mathbf{N i}$ & $\mathrm{Si}$ & $\mathrm{Cr}$ & $\mathrm{C}$ & $\mathrm{S}$ & $\mathrm{P}$ & $\mathrm{Fe}$ \\
\hline Новая Каледония & $\mathbf{1 6 , 8 9}$ & 1,93 & 1,29 & 2,84 & 0,3 & 0,02 & Остальное \\
\hline Индонезия & $\mathbf{1 8 , 5 1}$ & 4,02 & 1,53 & 2,55 & 0,26 & 0,0313 & Остальное \\
\hline Гватемала (старая технология) & $\mathbf{1 3 , 4 1}$ & 3,41 & 2,11 & 2,79 & 0,17 & 0,053 & Остальное \\
\hline Гватемала (ТВП) & $\mathbf{3 7 , 3 0}$ & 0,01 & 0,04 & 0,03 & 0,48 & 0,064 & Остальное \\
\hline
\end{tabular}

Химический состав ферроникеля на РТП-1 и РТП-2, \%

Таблица 3

\begin{tabular}{|l|c|c|c|c|c|c|c|c|}
\hline & Ni & Co & Si & Cr & S & C & P & Cu \\
\hline РТП-1 & $\mathbf{4 7}$ & 0,42 & 0,01 & 0,02 & 0,5 & 0,014 & 0,065 & 0,063 \\
\hline РТП-2 & $\mathbf{1 4 , 5}$ & 0,27 & 3,90 & 1,8 & 0,25 & 2,5 & 0,064 & 0,032 \\
\hline
\end{tabular}


многокомпонентной системы с использованием современной программы «HSC Chemistry 6,0», разработанной специалистами исследовательского центра фирмы Outotec.

Результаты выполненных расчетов энергий Гиббса при стандартных условиях реакций представлены ниже:

1. $3 \mathrm{Na}_{2} \mathrm{CO}_{3}+2 \mathrm{Si}+\mathrm{FeS}=2 \mathrm{Na}_{2} \mathrm{SiO}_{3}+\mathrm{Na}_{2} \mathrm{~S}+\mathrm{Fe}+3 \mathrm{CO}$, $\Delta G_{T}^{0}=-326578+430 T$, КДж/моль;

2. $3 \mathrm{Na}_{2} \mathrm{CO}_{3}+2 \mathrm{Si}+\mathrm{NiS}=2 \mathrm{Na}_{2} \mathrm{SiO}_{3}+\mathrm{Na}_{2} \mathrm{~S}+\mathrm{Ni}+3 \mathrm{CO}$, $\Delta G_{T}^{0}=-340447+440 \mathrm{~T}$, КДж/моль;

3. $\mathrm{Na}_{2} \mathrm{CO}_{3}+\mathrm{C}+\mathrm{FeS}=\mathrm{Fe}+\mathrm{Na}_{2} \mathrm{~S}+\mathrm{CO}+\mathrm{CO}_{2}$, $\Delta G_{T}^{0}=-362121+330 \mathrm{~T}, \mathrm{KДж/моль;}$

4. $3 \mathrm{Na}_{2} \mathrm{CO}_{3}+\mathrm{Si}+2 \mathrm{FeS}+3 \mathrm{C}=\mathrm{Na}_{2} \mathrm{SiO}_{3}+2 \mathrm{Na}_{2} \mathrm{~S}+$

$+2 \mathrm{Fe}+6 \mathrm{CO}$

$\Delta G_{T}^{0}=-638017+971 \mathrm{~T}$, КДж/моль;

5. $3 \mathrm{Na}_{2} \mathrm{CO}_{3}+\mathrm{Si}+2 \mathrm{NiS}=\mathrm{Na}_{2} \mathrm{SiO}_{3}+2 \mathrm{Na}_{2} \mathrm{~S}+2 \mathrm{Ni}+$ $+3 \mathrm{CO}_{2}$,

$\Delta G_{T}^{0}=-610277+990 \mathrm{~T}$, КДж/моль;

6. $\mathrm{Na}_{2} \mathrm{CO}_{3}+\mathrm{NiS}+\mathrm{C}=\mathrm{Ni}+\mathrm{Na}_{2} \mathrm{~S}+\mathrm{CO}(г)+\mathrm{CO}_{2}(г)$, $\Delta G_{T}^{0}=-348251+340 \mathrm{~T}$, КДж/моль;
Анализ полученных результатов показывает, термодинамически влияние на десульфурацию кремния в системе более эффективно в сравнении с углеродом (рис. 1). Хотя некоторые специалисты-производственники отмечают, что более значительное влияние на процесс десульфурации оказывает именно углерод, что, по-видимому, связано с кинетическими параметрами процесса - влияние газовой фазы (содержание СО) на перемешивание реагентов и увеличение их контактной поверхности.

Процесс интенсивной десульфурации сульфида никеля начинается при температуре $500{ }^{\circ} \mathrm{C}$ и заканчивается при температуре около $1000{ }^{\circ} \mathrm{C}$, а сульфид железа при $750{ }^{\circ} \mathrm{C}$ и $1250-1350{ }^{\circ} \mathrm{C}$ соответственно (рис. 2).

Степень десульфурации никеля содой составляет 94-96 \%, а железа всего 60 \%, и с повышением температуры процесса выше $1350{ }^{\circ} \mathrm{C}$ происходит его ресульфурация.

Полученная термодинамическая модель распределения соединений в системе $\mathrm{FeS}$ - NiS $\mathrm{Na}_{2} \mathrm{CO}_{3}-\mathrm{C}$ - Si (рис. 3) позволяет определить

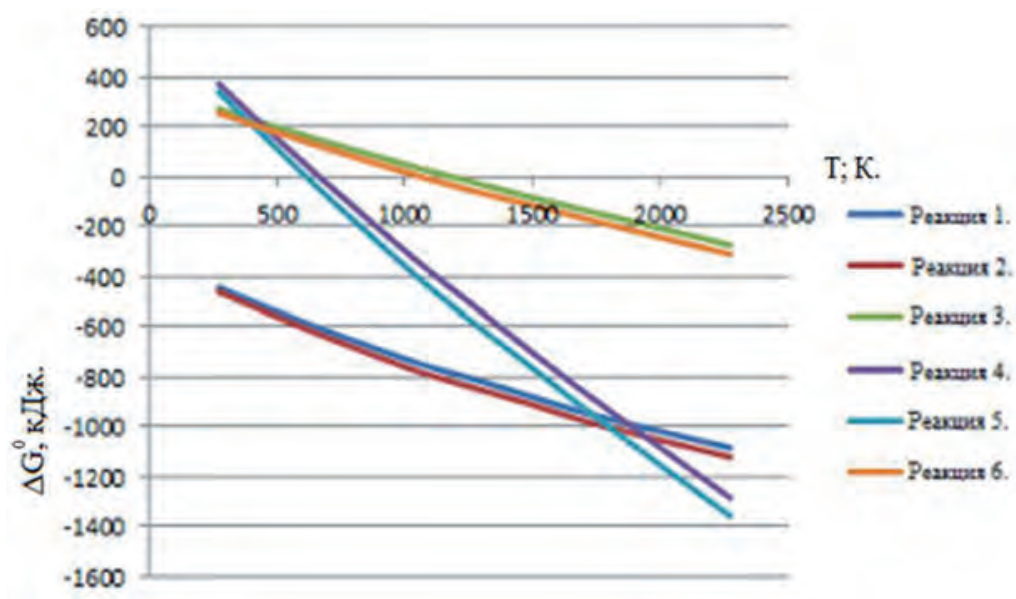

Рис. 1. Стандартные изменения энергии Гиббса для реакции десульфурации ферроникеля

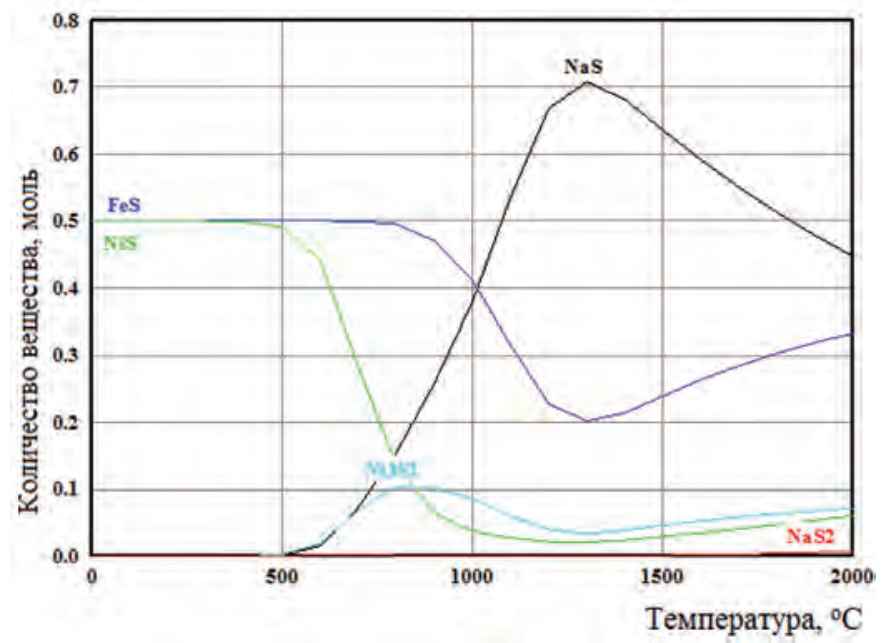

Рис. 2. Термодинамическая вероятность распределения сернистых соединений в системе $0,5 \mathrm{FeS}+0,5 \mathrm{NiS}+3 \mathrm{Na}_{2} \mathrm{CO}_{3}$

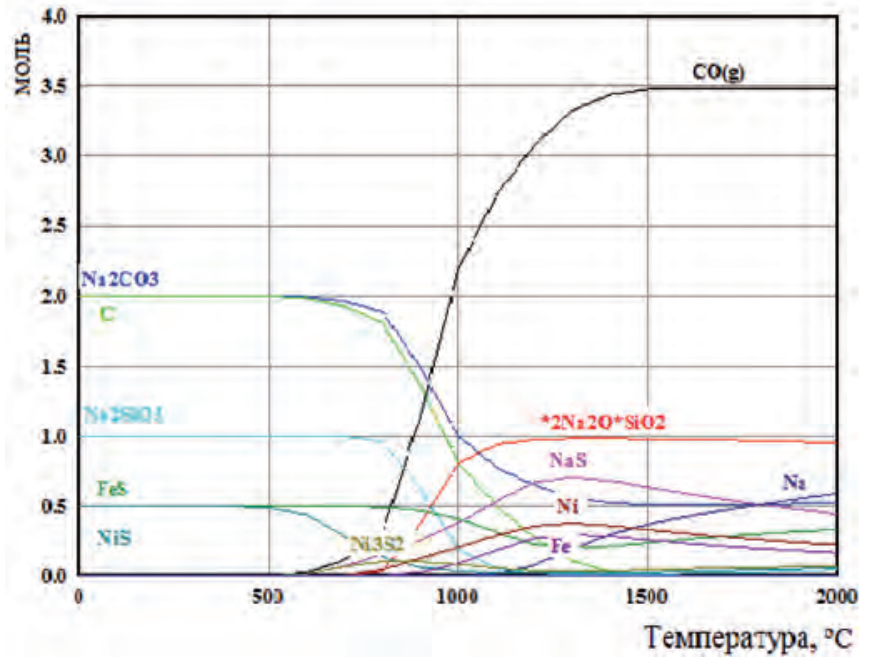

Рис. 3. Влияние температуры на распределение соединений в системе $\mathrm{FeS}-\mathrm{NiS}-\mathrm{Na}_{2} \mathrm{CO}_{3}-\mathrm{C}-\mathrm{Si}$ 
оптимальный температурный режим ковшевой десульфурации ферроникеля содой, который находится в пределах 1300-1350 C.

Окончательная десульфурация, рафинирование и доводка ферроникеля до требований стандарта осуществляется в конверторах.

\section{Выводы}

1. Производство ферроникеля по технологии низкого восстановления (ТНВ) позволяет получать сплав, содержащий до 50 \% Ni, до 0,01% Si и C, которые оказывают определяющее влияние на процесс его десульфурации содой в ковше при выпуске металла.

2. Термодинамический анализ реакций, протекающих в многокомпонентной системе внепечной десульфурации чернового ферроникеля, позволил установить, что основное влияние на процесс снижения концентрации серы в сплаве оказывает кремний.

3. На основании обработки промышленных данных с помощью программы «HSC Chemistry 6,0» впервые получена термодинамическая модель процесса десульфурации чернового ферроникеля кальцинированной содой в ковше, что позволило установить степень десульфурации основных составляющих сплава - Ni и Fe, которая составляет 95 и 60 \% соответственно, а также определить оптимальный температурный режим для процесса десульфурации, находящийся в пределах $1300-1350{ }^{\circ} \mathrm{C}$.

\section{Библиографический список / References}

1. Исследование химического минералогического состава никелевых руд для выплавки ферроникеля / Н. В. Новиков, И. И. Капран, К. Д. Соколов, М. И. Гасик, А. Н. Овчарук // Металлургическая и горнорудная промышленность. - 2005. - № 3. - C. 19-22.

Novikov N. V., Kapran I. I., Sokolov K. D., Gasik M. I., Ovcharuk A. N. Issledovanie khimicheskogo mineralogicheskogo sostava nikelevykh rud dlya vyplavki ferronikelya. Metallurgicheskaya i gornorudnaya promyshlennost'. 2005, no. 3, pp. 19-22.

2. Восстановительная смесь для электротермического производства ферроникеля. Патент Украины № 109001 от 10.08.2016г. Бюл. № 15, авт. Беспалов О. Л., Приходько С. В., Данов О. В. и др.

Bespalov O. L., Prikhod'ko S. V., Danov O. V. Vosstanovitel'naya smes' dlya elektrotermicheskogo proizvodstva ferronikelya. Patent Ukrainy No. 109001 10.08.2016g. Byul. No. 15.

3. Современное состояние и перспективы совершенствования технологии производства ферроникеля / О. Л. Беспалов, К. Д. Соколов, С. В. Приходько, О. В. Замковой, Д. А. Шевченко, С. А. Мельник, Н. Н. Новиков, Д. С. Овчарук, В. В. Солоха // Актуальные проблемы развития металлургической науки и образования. - 2017. C. 204-211.

Bespalov O. L., Sokolov K. D., Prikhod'ko S. V., Zamkovoy O. V., Shevchenko D. A., Mel'nik S. A., Novikov N. N., Ovcharuk D. S., Solokha V. V. Sovremennoe sostoyanie i perspektivy sovershenstvovaniya tekhnologii proizvodstva ferronikelya. Aktual'nye problemy razvitiya metallurgicheskoy nauki i obrazovaniya. 2017, pp. 204-211.

4. Гасик М. И. Физикохимия и технология электроферросплавов: учебник для ВУЗов / М. И. Гасик, Н. П. Лякишев. - М.: СП Интермет Инжиниринг, 2008. - 453 с.

Gasik M. I., Lyakishev N. P. Fizikokhimiya $i$ tekhnologiya elektroferrosplavov. Mscow, SP Intermet Inzhiniring, 2008453 p.

5. Диомидовский Д. А. Металлургия ферроникеля / Д. А. Диомидовский, Б. П. Онищин, В. Д. Линев. - М.: Металлургия, 1983. - 184 с.

Diomidovskiy D. A., Onishchin B. P., Linev V. D. Metallurgiya ferronikelya. Moscow, Metallurgiya, 1983, $184 \mathrm{p}$.

Mета. Дослідження типу і хімічного складу неметалевих включень при процесі десульфурації чорнового фреронікелю методом складання термодинамічної моделі процесу десульфурації чорнового фреронікелю.

Методика. Виконано аналіз впливу кремнію і вуглецю в термодинамічній системі на процес десульфурації чорнового фреронікелю.

Наукова новизна. Вперше складено термодинамічну модель десульфурації чорнового феронікелю в ковші за схемою $\mathrm{NiS}-\mathrm{FeS}-\mathrm{C}-\mathrm{Si}-\mathrm{Na2CO} 3$ використанням даних промислового виробництва в умовах ТОВ «Побузький феронікелевий комбінат».

Ключові слова: чорновий феронікель, нікелева сировина, сірка, вуглець, кремній, кальцинована сода, десульфурація, термодинамічна модель.

Purpose. Studies of the type and chemical composition of non-metallic inclusions in the process of desulfurization of a rough ferronickel by compiling a thermodynamic model of the process of desulfurization of a rough ferronickel.

Methodology. The analysis of the effect of silicon and carbon in a thermodynamic system on the process of desulfurization of a rough feronikel is performed.

Practical value. For the first time, a thermodynamic model of desulfurization of a rough ferronickel in a ladle according to the NiS - FeS - C - Si - Na2CO3 scheme was compiled using industrial production data under the conditions of LLC Pobuzhsky Ferronickel Combine.

Key words: rough ferronickel, nickel raw materials, sulfur, carbon, silicon, soda ash, desulfurization, thermodynamic model.

Рекомендована к публикации д. т. н. А. С. Вергуном

Поступила 21.09.2018 